\title{
Marek's disease virus and skin interactions
}

\author{
Mathilde Couteaudier and Caroline Denesvre*
}

\begin{abstract}
Marek's disease virus (MDV) is a highly contagious herpesvirus which induces T-cell lymphoma in the chicken. This virus is still spreading in flocks despite forty years of vaccination, with important economical losses worldwide. The feather follicles, which anchor feathers into the skin and allow their morphogenesis, are considered as the unique source of MDV excretion, causing environmental contamination and disease transmission. Epithelial cells from the feather follicles are the only known cells in which high levels of infectious mature virions have been observed by transmission electron microscopy and from which cell-free infectious virions have been purified. Finally, feathers harvested on animals and dust are today considered excellent materials to monitor vaccination, spread of pathogenic viruses, and environmental contamination. This article reviews the current knowledge on MDV-skin interactions and discusses new approaches that could solve important issues in the future.
\end{abstract}

\section{Table of contents}

1. Introduction

2. Marek's disease virus

3. Pathophysiology of Marek's disease

4. Chicken skin and feather follicles

4.1. Chicken skin structure

4.2. The feather follicle: the organ that generates feathers

5. Feather follicles support the excretion and horizontal transmission of MDV

6. Methods for MDV detection in the skin or feathers (diagnostic methods)

7. MDV replication in feather follicles

8. MDV tropism for feather follicles - hypotheses

9. Impact of host genetics on MDV replication in the skin

10. Cutaneous lesions after MDV infection

11. Atypical morphogenesis of MDV in the skin

12. Viral molecules associated with MDV replication in feather follicles or with the infectiousness of particles excreted from the skin

13. Excretion of vaccinating strains and pathogenic strains of MDV

14. Immune response in the skin of MDV-infected chickens

15. Conclusions

16. Abbreviations

* Correspondence: denesvre@tours.inra.fr

INRA, UMR1282, Infectious Diseases and Public Health, ISP, BIOVA team, F-37380 Nouzilly, France

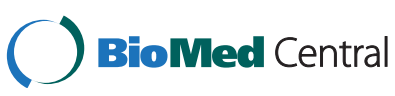

17. Lexicon

18. Competing interests

19. Authors' contributions

20. Acknowledgements

21. References

\section{Introduction}

Marek's disease virus (MDV), or Gallid herpesvirus 2 $(\mathrm{GaHV}-2)$ is the etiological agent responsible for Marek's disease (MD) in the chicken, a multifaceted disease most widely recognized by the induction of a rapid and extensive malignant T-cell lymphoma. MD has been shown to occur worldwide according to data from the world Organization for Animal Health (OIE), although data are difficult to obtain because this disease is not a notifiable disease. MD results in substantial economic losses, estimated at more than 1 billion per year [1]. Although MD was described in 1907 by Joseph Marek, the virus (MDV) was only isolated in 1967 in the United Kingdom [2] and the United States [3] independently. MDV belongs to the family of Herpesviridae, the subfamily of Alphaherpesvirinae, and the genus Mardivirus (for Marek's disease-like viruses). MDV was initially classified within the Gammaherpesvirinae due to its biological properties, but was reclassified in 2002 (after the complete sequencing of its genome) in the new Mardivirus genus, for which it became the type-species [4]. To date this genus comprises 4 other species: the Gallid herpesvirus 3 (GaHV-3), the Meleagrid herpesvirus 1 (MeHV-1) commonly known as herpesvirus of turkey (HVT), the Anatid herpesvirus 1 and the Columbid herpesvirus 1 . 
GaHV-3 and HVT infect domestic fowls like MDV, but are not pathogenic.

MDV is the first oncogenic virus for which an effective vaccine has been developed, in the late sixties [5-7]. In the early seventies, when large scale vaccination started in poultry houses, MDV was responsible for a large mortality and morbidity. Since this time, vaccination has allowed the thriving industrial production of eggs and poultry meat. All the currently used vaccines are live vaccines derived from the three viral strains: the HVT FC126 strain [7], the GaHV-3 SB-1 strain [8], and the GaHV-2 CVI988/Rispens strain [9]. HVT and SB-1 vaccines are considered heterologous vaccines because they are derived from a different viral species than the virus it is intended to protect against, while the Rispens vaccine is considered homologous because it is from the same viral species as the targeted virus.

\section{Marek's disease virus}

Herpesvirus infectious particles comprise more than 30 different proteins, assembled according to a complex architecture including the following: (i) a central capsid containing the viral genome, (ii) a protein layer termed tegument, comprising more than 15 proteins, and (iii) a lipid bilayer in which about 10 envelope glycoproteins are anchored. The MDV genome is a linear doublestranded DNA of approximately $175 \mathrm{~kb}$, which contains a unique long (UL) sequence and a unique short (US) sequence, both flanked with terminal repeat (TR) and internal repeat (IR) sequences [4]. Owing to its structure, this genome belongs to group $\mathrm{E}$, like the human herpesvirus 1 (HHV-1). The MDV genome contains about 100 open reading frames and encodes more than 70 genes, most of which have orthologous equivalents in other alphaherpesviruses (e.g., tegument genes like UL36 [VP1/ 2], the largest ORF in the genome, UL47 [VP13/14] and UL49 [VP22] or capsid genes like UL19 [VP5]) [4]. However, some genes are specific to MDV, such as the gene encoding Meq oncoprotein or pp38 phosphoprotein [4].

To date, MDV replicates efficiently only in primary chicken or duck cells in culture [2,3], yielding titers between $10^{5}$ and $10^{7} \mathrm{pfu} / \mathrm{mL}$ depending on the strain. MDV infections are performed by co-culturing infected cells with naïve cells because the virus cannot be purified as cell-free virus from cell lysates or culture supernatants. These different characteristics constitute constraints for vaccine production.

\section{Pathophysiology of Marek's disease}

The current model of MD pathophysiology was initially proposed by Bruce Calnek [10,11]. This model is described in Figure 1. MDV enters via the chicken respiratory tract after inhalation of contaminated dust. Then MDV infects B lymphocytes and macrophages in the

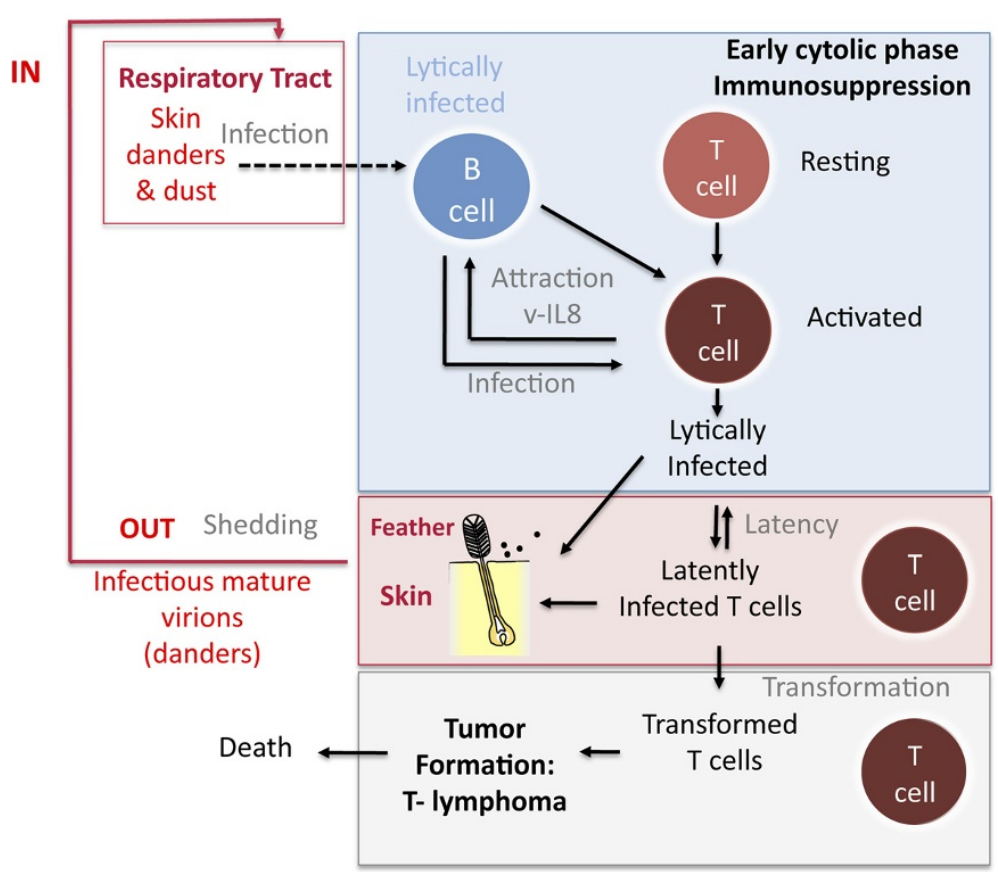

Figure 1 Pathophysiology of Marek's disease (adapted from Calnek model [10,11]). Marek's disease virus (MDV) enters into the chicken through the respiratory tract. MDV has a tropism for B- and T- lymphocytes as well as for the feather follicle epithelium, from which MDV is shedded into the environment. Feathers, skin danders and dust are the major source of MDV infectious materials and the basis of horizontal bird-to-bird transmission in field conditions. 
lungs [12] and is then transported towards the main lymphoid organs (bursa of Fabricius (see lexicon), thymus, and spleen). After replicating in B lymphocytes, MDV infects activated $\mathrm{T}$ lymphocytes, mainly CD4+ cells. It is believed that only a few $\mathrm{T}$ lymphocytes undergo transformation and are at the origin of the $\mathrm{T}$ lymphoma, which may be either monoclonal or oligoclonal [13]. This lymphoma is mostly localized in visceral organs (kidneys, spleen, liver, gonads, and proventriculus), peripheral nerves, skin, and muscles. In most transformed $\mathrm{T}$ lymphocytes, the virus is in latent phase and does not produce viral particles. Only a small proportion of tumor cells $(<0.01 \%)$ expresses lytic viral antigens and contains viral particles detectable in transmission electron microscopy (TEM) [14]. Of note, MDV only enters latency in lymphocytes but not in neurons, like most alphaherpesviruses. Early during infection, the virus is transported towards the skin, most specifically to feather follicles. From infected feather follicles, MDV is shed into the environment via scales and feather debris, which become the major source of contamination of other birds in the natural environment. Bird-tobird transmission is exclusively horizontal. There is no vertical transmission from the chicken to the egg, even though the embryo can be experimentally infected [15]. In typical housing conditions, it is believed that animals become contaminated at a young age. MDV interactions with chicken skin is considered the major cause of MDV persistence in poultry houses and its evolution towards increasingly more virulent genotypes has been observed for the past decades $[16,17]$. To this end, in this review we present the current state of knowledge of MDV interactions with chicken skin. For other aspects of MDV biology, we refer the reader to other reviews [18-20].

\section{Chicken skin and feather follicles}

\section{1. Chicken skin structure}

In vertebrates, the skin is the first layer of protection against the external environment. The skin plays an important role in thermal, hygrometric, and chemical regulation. Bird's skin differs from that of mammals by its thinness, by the presence of feathers instead of hair, and by the absence of sebaceous glands, although the overall histological structure is similar [21,22]. Bird's skin is composed of an epidermis separated from a dermis by a basal membrane (Figures 2 and 3). Table 1 presents the cell markers mentioned in this review that are used to characterize the various skin layers; these markers are generally defined by their homology to that of mammals, based on their DNA sequence. The basal membrane is a thin and continuous layer which serves as a molecular filter and anchoring point for the epidermis basal cells via hemidesmosomes. This extracellular matrix is mainly constituted of type IV collagen and proteoglycans. Bird dermis is relatively thin compared to that of mammals. It is mainly constituted of connective tissue arranged in a superficial layer (or stratum superficiale) and a deep layer (or stratum profundum). The dermis can be identified by the expression of cell markers such as fibronectins. The epidermis is a multistratified, keratized squamous epithelium, whose thickness varies depending on the region of the body. The epidermis deep layer (stratum germinativum) is composed of live cells arranged in three layers: the basal, intermediate, and transitional layers (Figure 2). The basal layer, which is next to the basal membrane, is constituted of small undifferentiated cubic cells, which have a high dividing rate and which migrate towards more superficial layers. The basal layer can be identified with cell markers such as basonuclin 2, keratins 5 and 14 [23,24] (Figure 2B).
A

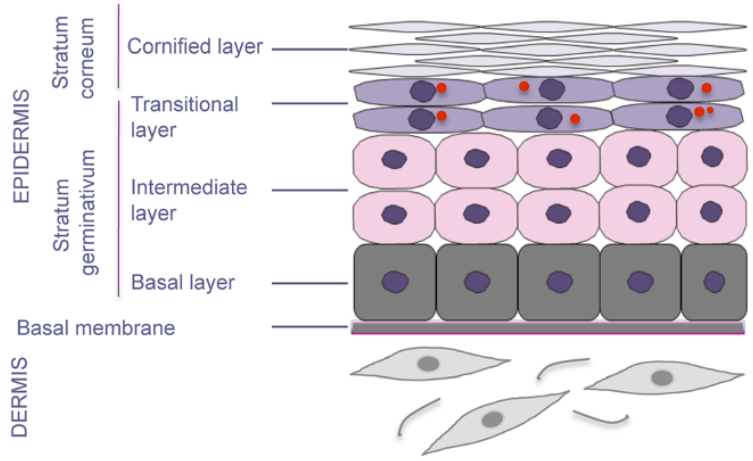

B

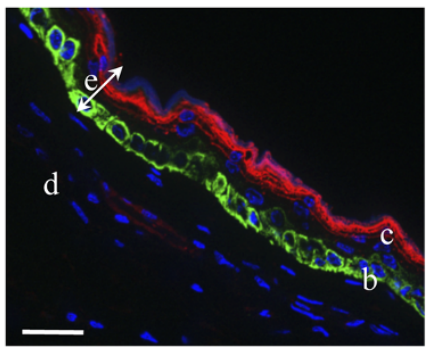

Figure 2 Structure of chicken apteric skin. (A) Schematic chicken skin section without feather follicle. The epidermis is constituted of four layers with keratinocytes at various differentiation stages. The red circles represent lipid droplets. (B) Expression and localization of two markers of the epidermis, involucrin (red) and keratin 14 (green), detected by immunofluorescence. The skin was harvested from a 53-day old white leghorn chicken, fixed in 4\% paraformaldehyde, frozen and embedded in cryomatrix compound. Seven $\mu$ m-thick cryosections were stained with two antibodies: anti-keratin 14 (green) and anti-involucrin (red). Secondary antibodies used were conjugated to Alexafluor 488 or 594 . The nuclei were stained with Hoechst 33342 dye (blue). Images were captured on an Axiovert $200 \mathrm{M}$ inverted epi-fluorescence microscope in the presence of the

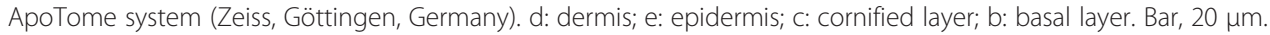



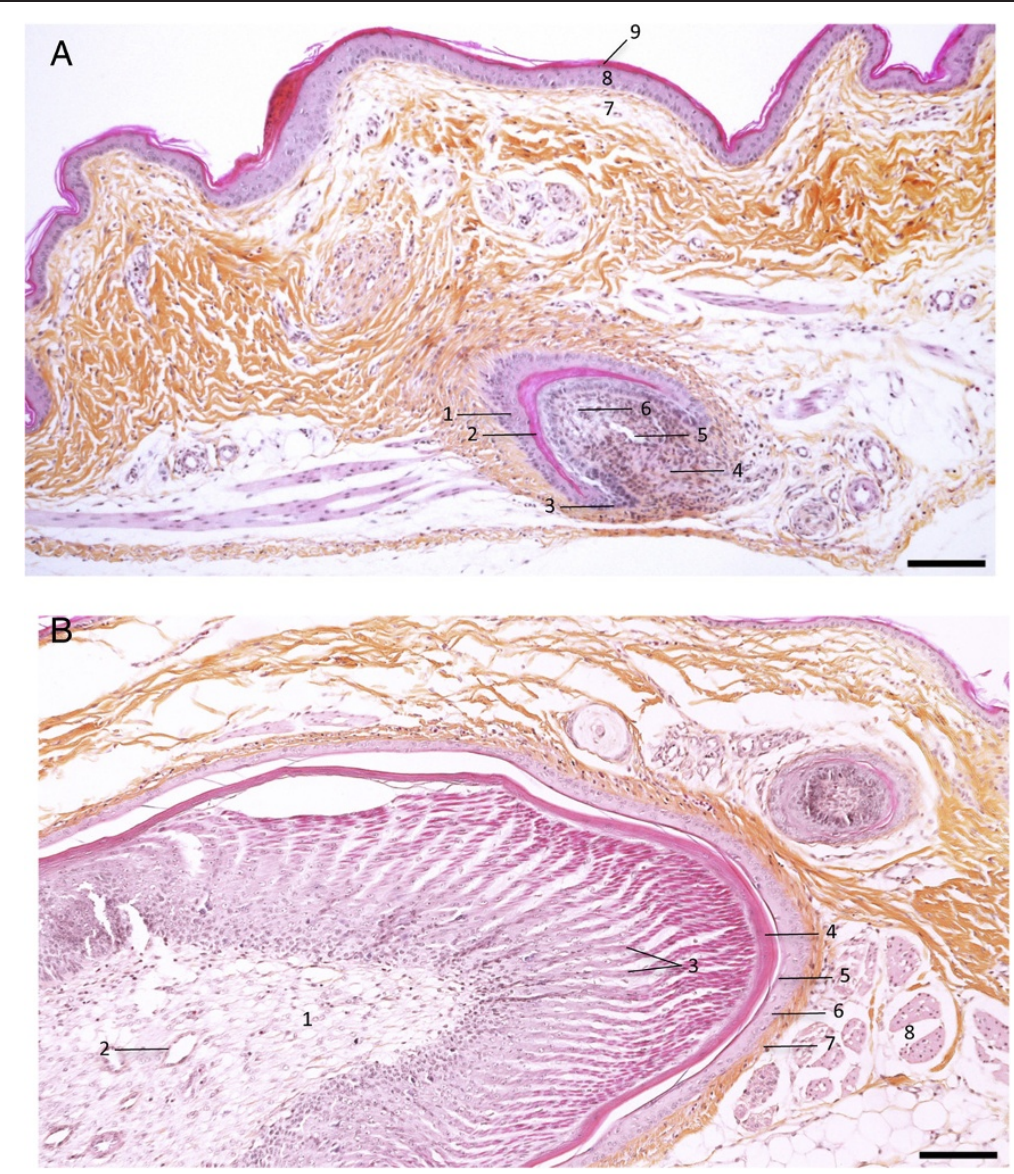

Figure 3 Chicken skin with feathers. The skin from a 53-day old white Leghorn chicken, was harvested, fixed in 4\% paraformaldehyde, and embedded in paraffin. Sections were stained with hematoxylin, eosin, saffron. (A) Skin region with a feather follicle. Feather follicle (1 to 6); skin (7 to 9): 1, feather follicle; 2, cornified cells; 3, epidermal collar; 4, dermal papilla; 5, axial blood vessel; 6, Feather pulp; 7, Dermis of the skin; 8, stratum germinativum of the skin; 9 , stratum corneum of the skin. (B) A growing feather: 1, feather pulp; 2, axial blood vessel; 3, barbs; 4, feather sheath; 5, stratum corneum (follicle); 6, stratum germinativum (follicle); 7, Dermis; 8, muscle feather. Bar, 100 um. (Pictures kindly provided by T. Larcher).

The intermediate layer is constituted of cubic cells that have migrated from the basal layer. The bird's intermediate layer is similar to mammal's spinous layer. The intermediate layer can be detected via the expression of transglutaminase 5 or desmoglein 2 [25]. The transitional layer is constituted of two or three layers of flat elongated cells containing a large number of intracellular lipid vacuoles or droplets, which is typical of bird's skin. This layer expresses keratin 10 and 75 (alpha-keratin KIIB) [24,26]. The external layer of the epidermis or cornified layer (also called stratum corneum) is composed of corneocytes, which are flat dead anucleated keratinized cells organized in sheets. This layer can be identified by the presence of involucrin, loricrin, or filaggrin [27] (Figure 2B). The differentiation of basal cells in corneocytes is a normal physiological process in the epidermis. The main cellular modifications are the loss of organelles, the formation of lipid vacuoles and keratin fibers in the cytoplasm and a thick envelope under the plasma membrane [22]. Corneocytes, which detach regularly from the epidermis, are constantly renewed by the cells from the lower layers. This process called exfoliation or desquamation results from the loss of desmosomes between corneocytes.

As in mammals, chicken epidermis contains dendritic cells (Langerhans cells), whose number is estimated at 8000 per $\mathrm{mm}^{2}$ of epidermis in an 8-week chick [28,29]. These two studies were conducted in the apteric areas (see lexicon) of the skin that have no feathers. Following antigenic stimulation, these cells seem to migrate to dermal lymphoid nodules, and not to lymph nodes that are absent in birds [29]. Besides feathers, bird's epidermis contains melanocytes, including in non-colored chickens. The "silky-chicken" strains, which have a dark skin and white or black feathers ("white silky" or "black silky"), are the only strains that also have a large number of melanocytes in the dermis and in the connective tissue of deep organs [30].

\section{2. The feather follicle: the organ that generates feathers}

Birds are the only animals for which feathers are absolutely necessary for flying but also act as a thermal 
Table 1 Cellular markers of chicken skin

\begin{tabular}{|c|c|c|}
\hline Cell layers of the skin & Cellular markers & Functions \\
\hline Dermis & Fibronectin & $\begin{array}{l}\text { Glycoprotein which contributes to extracellular matrix organization and } \\
\text { favors cell adherence }\end{array}$ \\
\hline Basal membrane & Laminin & $\begin{array}{l}\text { Protein complex, an essential component from the basal membrane, } \\
\text { which constitutes a molecular filter }\end{array}$ \\
\hline \multirow[t]{3}{*}{ Basal layer of epidermis } & Basonuclin 2 & $\begin{array}{l}\text { Nuclear protein with zinc fingers, transcription factor which maintains the } \\
\text { proliferative ability and prevents the terminal differentiation }\end{array}$ \\
\hline & Keratin 5 (KRT5) & $\begin{array}{l}\text { a-keratin type II, intermediate filament of proliferating keratinocytes, } \\
\text { associated to KRT14 }\end{array}$ \\
\hline & Keratin 14 (KRT14) & $\begin{array}{l}\text { a-keratin type I, intermediate filament of proliferating keratinocytes, } \\
\text { associated to KRT5 }\end{array}$ \\
\hline \multirow[t]{2}{*}{ Intermediate layer of epidermis } & Transglutaminase 5 & $\begin{array}{l}\text { Calcium dependent-enzyme involved in the first differentiation steps of } \\
\text { the epidermis }\end{array}$ \\
\hline & Desmoglein 2 & $\begin{array}{l}\text { Cadherin playing a role in the formation of desmosomes, that connect } \\
\text { together epithelial cells }\end{array}$ \\
\hline \multirow[t]{2}{*}{ Transitional layer of epidermis } & Keratin 75 (KRT 75) & $\begin{array}{l}\text { a-keratin type IIB, marker from the terminal differentiation of the } \\
\text { keratinocytes }\end{array}$ \\
\hline & Keratin 10 (KRT10) & $\begin{array}{l}\text { a-keratin type I, marker from the terminal differentiation of the } \\
\text { keratinocytes, associated to keratin } 1\end{array}$ \\
\hline \multirow[t]{3}{*}{ Cornified layer of epidermis } & Involucrin & Precursor protein from the corneocyte envelope \\
\hline & Filaggrin & Basic protein associated to keratin filaments of the cornified layer \\
\hline & Loricrin & Precursor protein from the corneocyte envelope \\
\hline
\end{tabular}

barrier. Feathers are the most complex and most diversified integumentary products found in vertebrates. Feathers are exclusively constituted of $\beta$-keratin [31] and arise from the feather follicle. The feather follicle forms by invagination of the epidermis around the feather filament cylinder into the dermis, at day 14 of embryogenesis, which lasts 21 days in chickens [32]. There are as many feather follicles as there are feathers on the skin, i.e., between 20000 and 80000 depending on the bird species [32]. At the base of the feather follicle are located the dermal papilla, the epidermal collar and the collar bulge (Figure 3). Follicle stem cells, which are located in the collar bulge, give rise to a population of transient amplifying (TA) cells, which allow the renewal of the feather and the follicle after molting or after accidentally plucking the feather [33,34]. Repeated molting ensures the regular renewal of bird feathers throughout its lifespan.

Feather follicles contain melanocytes responsible for the color of the feathers, as well as melanocyte stem cells, which were recently identified by the Chuong laboratory [35]. In a regenerating follicle, melanocyte stem cells (pigmented or not) are located in the epithelium, above the dermal papilla, in the lower part of the bulge. In a resting feather follicle, melanocyte progenitors move into the dermal papilla, where they remain quiescent [35].

At the feather level, pulp cells originate from the dermal papilla cells, while all other cells derive from the epidermal collar and the collar bulge [32]. The base of the feather is vascularized by an arteriole which goes through the dermal papule and the pulp of the feather (Figure 3).

\section{Feather follicles support the excretion and horizontal transmission of MDV}

It has been known since 1963 that, in natural conditions, disease transmission is airborne [36,37], suggesting that the virus is excreted and relatively resistant in the external environment. Moreover, the observation of cutaneous lesions in birds with MD and the detection of MDV antigens via immunofluorescence in feather follicles led early on to the suspicion that feather follicles were involved in the excretion of the virus [38]. In 1970, it was shown that dust, scales, and feather debris collected in infected poultry houses could lead to MD after intraabdominal administration to chicks or after introduction in the confined environment of healthy chickens $[39,40]$. The presence of infectious virions in the skin and feather follicles of infected chickens was confirmed a few months later by the teams of Calnek and of Nazerian $[41,42]$. To this end, skin or feather tip homogenates of infected chickens were observed using negative TEM. When administered to healthy chickens this material was capable of reproducing MD. These findings demonstrated that the feather follicle can produce complete mature infectious virions, harboring a tegument and an envelope. Still today feather follicles constitute the only biological material that allows the extraction of enveloped infectious virions and transmission of the infection in the absence of associated cells. The infectiousness of 
MDV in the environment can last up to 7 months at room temperature [43] and 16 weeks in litters [44], a duration that is unusual for a herpesvirus. These findings suggest that infectious viral particles are probably not in direct contact with the environment but physically protected from degradation, possibly by cellular material (see the section regarding viral morphogenesis below).

\section{Methods for MDV detection in the skin or feathers (diagnostic methods)}

In this paragraph we will only cite the methods that were applied to MDV detection in the skin and/or feathers. Until the 1980s, these methods were aimed at detecting viral antigens by immunofluorescence on tissue sections [38], or by gel immunodiffusion or ELISA from feather tip cell extracts $[45,46]$. In the 1960s and $70 \mathrm{~s}$, these antigens were detected using the serum of infected chickens. Today, polyclonal serums and monoclonal antibodies against single viral proteins are also available. TEM has been used to visualize viral particles in situ in the skin or in tissue extracts (see section on viral morphogenesis below). Since the 1990s, new methods based on molecular biology techniques have appeared, enabling mardivirus genome detection (PCR) $[47,48]$ and quantification (qPCR) [49-52]. It is also possible to detect viral DNA in feathers by pulse field gel electrophoresis (PFGE) [53] or via in situ hybridization [54]. An inexpensive and rapid method of amplification of the viral genome called LAMP (loop-mediated isothermal amplification) has been recently developed to allow rapid diagnostic in field conditions [55]. The substantial improvement of sequencing techniques has also allowed the direct sequencing of viral DNA extracted from feather tips to detect coinfections for instance [56]. Moreover, PCR methods allow the detection and quantification of viral DNA in dust collected and concentrated on filters $[51,57,58]$. Finally, MDV can also be re-isolated from feather pulp via co-culture in vitro [14]. To this end, the pulp is extracted from the base of the feather, digested using collagenase, and the resulting cell suspension is incubated with a monolayer of permissive cells.

For the past years, feathers and dust have been considered the material of choice to follow the evolution and distribution of pathogenic and vaccine strains of Mardiviruses in poultry houses [59]. Four to five pulp-rich feathers, preferably collected on the axillary tract, are sufficient to detect viral DNA using qPCR (S. Baigent personal communication).

\section{MDV replication in feather follicles}

Regarding viral antigen expression, the epithelium of feather follicles is the tissue the most commonly found positive in infected chickens, compared to other tissues $[38,45]$. It is also the infected tissue that expresses the highest level of viral antigens for the longest period of time. These antigens are located in the upper layers of the stratum germinativum of feather follicles (Figure 4). Viral antigens are detectable in feather follicles from feathers tips 11 to 14 days post-infection (pi) using standard biochemical methods $[60,61]$. With more sensitive methods such as qPCR, viral DNA can be detected as early as 6-7 days pi in feather tips and in dust

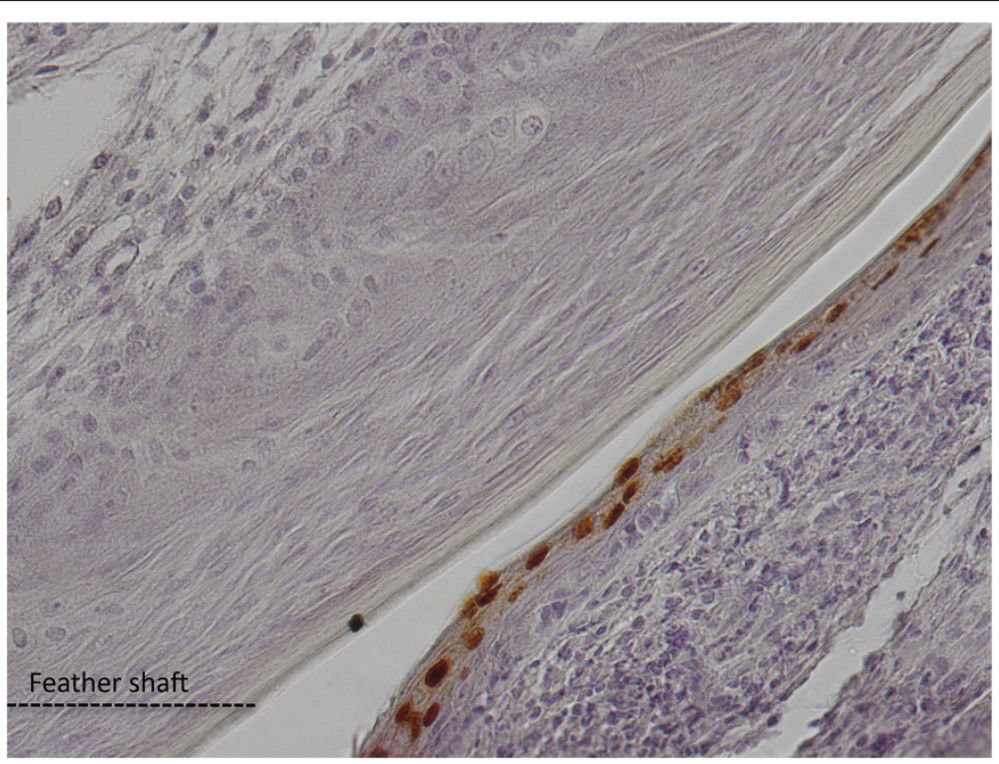

Figure 4 Detection of VP5 major capsid antigen in MDV infected feather follicle by immunohistochemistry. The VP5 protein is located in the nuclei of the upper layers from the feather follicle epithelium (brown nuclei), at the junction with the feather shaft. (Picture kindly provided by J-F. Vautherot). 
collected in isolation units [42,62,63]. A recombinant virus encoding the tegument gene UL47 fused with mRFP (monomeric Red Fluorescent Protein) allows the detection of lytic viral infection in feather follicles using fluorescence as early as day 8 pi [63]. The difference between the detection of the viral genome and its expression is due either to the difference in method sensitivity or to the delay between viral replication and the accumulation of late viral proteins to a sufficient level. The kinetics of replication of mardiviruses in feathers has been found to vary depending on the virus strain [63]. These variations do not seem to be directly linked to the strain's virulence, as it was formerly believed [42]. In fact, non-virulent strains can be detected in feathers and dust as early as highly virulent strains, and can even be excreted at higher levels $[62,64]$. It is noteworthy that excretion of MDV strains increases considerably from 7 to 28 days pi, reaching a plateau thereafter, according to quantitation experiments of viral genomes conducted on dust in isolation units [62]. Moreover, there is a strong correlation between the quantity of the MDV genome measured in feathers and dust [57].

Coinfection of birds with two pathogenic strains (regardless of their similarity of genotype or pathogenicity) leads to the replication of both viruses within the same feather follicle. This was demonstrated in several studies on feather follicle sections using fluorescence or immunohistochemistry utilizing viruses that have different antigenic markers or expressing different fluorescent reporter genes (e.g., GFP and mRFP) [56,65]. Jarosinski also showed that two fluorescent viruses with the same genotype can infect the same feather follicle cell [65]. This suggests that genetic recombinations between two different genomes could occur in the feather follicle to yield new strains. However, analysis of the frequency and distribution of two viral genomes after coinfection at different times pi by pyrosequencing has shown that some strains may preferentially replicate in feather follicles when compared to other strains [56].

\section{MDV tropism for feather follicles - hypotheses}

The mechanisms by which MDV infects skin and feather follicles are poorly understood. Because B and T lymphocytes are the major targets of MDV and are infected early on $[10,12]$, it is probable that these cells are the vehicle to feather follicle infection. However, this has not been formally demonstrated; therefore the involvement of other blood cells (e.g., macrophages and/or dendritic cells) cannot be excluded. In addition, for most pathogenic strains, replication starts at 1 week pi in the feather follicle, well before tumor development. Therefore, it is probable that it is not transformed cells that migrated into the skin, as at this time, there are no or very few transformed cells.
Regarding how the virus reaches the transitional layer of the feather follicle epithelium, many questions remain unanswered: Why is the virus mainly present in the epidermis of feather follicles and not in the epidermis of the whole skin? Is the epidermis infected directly or indirectly, via the dermis? Does the virus directly infect the epidermis upper layers, or does it enter the basal layer first and then replicate only when those differentiate? How does the virus cross the basal membrane?

Various speculative scenarios can be proposed: (i) "cargo" infected cells (lymphocytes or other) infiltrate the skin epithelium to transmit the virus to the upper epithelial cells of the epidermis, and the virus propagates to other neighboring cells and so on; or (ii) lymphocytes infiltrate the dermis or the dermal papilla, infects neighboring cells such as fibroblasts or melanocyte precursors, which in turn transmit the virus to the basal epithelial cells of the epidermis, in which case it requires MDV to cross the basal membrane; or (iii) lymphocytes directly infect the follicle stem cells located in the bulge of the feather follicle, and the infection spreads widely to TA cells (see section on feather follicle above) that are involved in the repair of the follicle wall and the feather during feather regeneration, a process that occurs frequently at a young age. The development of new techniques and methods such as transgenic chickens harboring fluorescent transgenes in specific cell lineages (lymphocytes or dendritic cells for instance), methods enabling the in vitro culture of chicken skin that mimic a multilayer epithelium, and biphotonic imaging on thick tissue should help answer these questions in the near future.

\section{Impact of host genetics on MDV replication in the skin}

All lines of Gallus gallus, including exotic ones [66,67], seem susceptible to MDV infection. Interestingly, in poultry houses, MD similarly affects chicken breeds for meat production and those for egg production, even though these two types of productions may not be equally affected in some countries due to breeding practices. Although some chicken genetic markers have been shown to be involved in the susceptibility or resistance of chickens to tumors [68,69], no marker so far has been shown to regulate viral production in the epithelium of feather follicles. Further research in this area may help reduce or block the excretion and spreading of pathogenic MDV strains.

Two chicken lines with mutations that affect their normal skin physiology, have particular patterns of skin interaction with MDV that merit attention. The first line is the "scaleless" line, which carries a recessive autosomal mutation sc (for "scale") and produces "naked" chickens lacking scales on their legs and harboring only a few sparse feather follicles. Administration of skin cell 
extracts from scaleless chickens 29 days after infection with a hypervirulent strain (686) to naive chickens indicates that epithelial cells not associated with feather follicles are capable of transmitting infection and producing infectious viral particles [70]. In that study, however, no result was presented regarding the ability of these birds to transmit MD horizontally to susceptible chickens or to chickens of the same genotype to determine whether these animals excrete infectious virions in the environment.

The second line is the Smyth (SL) line, which has colored feathers similarly to the Brown Leghorn; this line spontaneously develops an autoimmune disease leading to a depigmentation of regenerating feathers, which become white due to the death of melanocytes. This line is considered as an animal model for human vitiligo [71]. The depigmentation of SL birds occurs between 6 and 14 weeks of age in $70 \%$ to $95 \%$ of the birds. When birds were moved from one university to another, the phenotype was only observed in $10 \%$ of the population, suggesting the role of the environment in addition to genetic factors. To determine the reasons for this difference, the environment and breeding conditions in the two animal facilities were compared. Among three important differences, vaccination of the birds against MD using the heterologous HVT appeared to be the most important factor. Indeed, it has been shown that 20 week-old birds vaccinated with HVT had an incidence of vitiligo 4 times higher than non-vaccinated birds [72]. This puzzling result raises various hypotheses regarding the impact of HVT vaccination on the development of vitiligo, knowing that the HVT vaccine also penetrates and replicates in feather follicles [51,59]. In the SL line, depigmentation is associated with melanocyte death and with the presence of anti-melanocyte auto-antibodies; therefore, one hypothesis would be that HVT infects melanocytes or their precursors, leading to their death and triggering an auto-immune response against melanocyte markers. In other genetic backgrounds, infection of these cells may have no impact on feather color and remain unnoticed. However, the ability of chicken melanocytes or their precursors to become infected by MDV has never been reported to date.

\section{Cutaneous lesions after MDV infection}

Macroscopic and microscopic lesions have been observed on the skin of infected chickens at the feather follicles or near them. Two types of lesions have been found: tumor-like and non tumor-like lesions. It is noteworthy that it was the tumor-like cutaneous lesions (often incorrectly called cutaneous leucosis) observed in the slaughterhouse that led to the initial suspicion that the skin was the main infected tissue in MD [73]. Birds presented hypertrophied feather follicles with compact lymphoid aggregates in the dermis associated with capillaries upon microscopic examination. The presence of MDV in tumor-like lesions was subsequently confirmed by isolation of the virus in culture [74]. However, in situ, these cells do not generally harbor viral antigens detectable by immunofluorescence [75], and therefore appear to be latently infected-tumor cells. Interestingly, cutaneous tumors with large accumulations of lymphoblasts expressing the viral oncoprotein Meq have been observed in the dermis of scaleless chickens, suggesting that the presence of feather follicles is not required for the development of skin tumors [70]. Among non tumor-like lesions are the nuclear inclusion bodies typically found during lytically herpesvirus infections. These nuclear inclusions are only found in the upper layers of the feather follicle epithelium, and never in the basal layer $[42,45,75]$. The lesions are associated with the presence of viral antigens. Analysis of the distribution of feather follicles positive for MDV antigens and lymphoid cell aggregates shows that these two features are associated [75], and suggests that lymphoid cells could be the source of feather follicle infection, although this has not been demonstrated. Macroscopic and microscopic lesions associated with the presence of MDV antigens have been described in cutaneous structures other than feather follicles, including the comb, barbs, and leg skin that harbors scales without feathers [76]. For more details on these skin lesions, we refer the reader to two reviews $[20,77]$.

\section{Atypical morphogenesis of MDV in the skin}

All herpesvirus infectious particles have similar morphology, which consists of an icosaedric capsid containing the viral genome surrounded by the tegument and envelope. The particle, whose size differences depends mostly on the tegument's thickness, is 200-250 nm in diameter for the type-species viruses, HHV-1 and PRV (pseudorabies virus) [78]. The particles are the result of a complex assembly, also termed viral morphogenesis, which follows three models. The most common model is that of envelopment-deenvelopment [79-83]. The assembly starts in the nucleus where the genome is incorporated in the capsids. These mature capsids, also called type $\mathrm{C}$ capsids, are then transported in the cytoplasm after budding at the inner nuclear membrane and fusion with the outer nuclear membrane. The envelopment-deenvelopment process creates a primary enveloped particle in the perinuclear space during the intermediate step. After reaching the cytoplasm, the capsids bind to tegument proteins and are reenveloped by budding into a membrane-bound organelle, probably the trans-Golgi network. Mature enveloped particles are then released in the extracellular medium by exocytosis. For the type-species alphaherperviruses HHV1 or PRV, the number of mature viral particles in the 
cytoplasm and in the extracellular medium in various cell types is generally high. For MDV, mature viral particles are scarce in the cytoplasm (approximately $0.5 \%$ of total particles) [84] and have never been observed in the extracellular medium in cell culture. It is the same in the tissues of infected chickens, except skin (see review [85]). The skin has been shown to contain many MDV infectious particles in the epidermis of feather follicles in the transitional layer $[42,86,87]$. In these cells, particles are often within cytoplasmic inclusions constituted of electrondense amorphous material and lacking visible peripheral lipid membranes. At higher magnification, enveloped particles located in these inclusions are 200-250 nm in diameter and do not seem to be surrounded by a second membrane [42], like predicted by the second envelopment process model. Because these two characteristics are atypical of alphaherpesviruses, they raise various hypotheses regarding the mechanism of final envelopment and excretion of the virus into the external medium. Are MDV virions excreted from the keratinocytes via active exocytosis or do they remain trapped in these cells until their final differentiation into corneocytes, and are they excreted passively in the environment by the physiological process of desquamation? These questions remain to be answered. To this date, there is no cell system that allows reproducing in culture the atypical viral morphogenesis observed in this tissue, which is a hindrance to its study as well as the study of other associated cellular determinants and processes.

As mentioned above, in 1970 the teams of Calnek and Nazerian were able to isolate viral particles from the skin of infected chickens and to observe them using TEM $[41,42]$. To this end, tissues were homogenized in water through freeze-thaw or by sonication. In these conditions, more than $50 \%$ of the viral particles observed were enveloped and had a diameter of 273-400 nm [41]. The size of these viral particles seems abnormally high compared to their estimated size in situ in the epidermis; therefore, this may be an artifact of the virus extraction method in hypotonic medium.

\section{Viral molecules associated with MDV replication in feather follicles or with the infectiousness of particles excreted from the skin}

Many studies have attempted to characterize the genes and/or viral proteins preferentially expressed in feather follicles in order to explain the high rate of morphogenesis observed in this tissue. A few viral proteins are expressed at a higher level in the feather follicle compared with that in other cell types in vivo or in culture. For instance, glycoprotein gD (encoded by the US6 gene) which is not usually expressed in chick embryo fibroblasts (CEF) in culture [88], is expressed in 30\% to $50 \%$ of feather follicles positive for other viral antigens such as pp38 in experimentally infected chickens [61]. The role of gD expression in feather follicles is still unclear because the US6 gene is not required for MDV transmission between birds [89]. Tegument protein VP13/14 encoded by the UL47 gene is also strongly expressed in the epithelium of feather follicles of infected chickens, but is expressed weakly in the spleen and in CEF in culture [90]. However, the relationship between its high level of expression in the feather follicle and the high viral productivity in that tissue has not been investigated.

The major tegument VP22 protein encoded by UL49 also influences MDV horizontal dissemination. Indeed, fluorescent tagging of VP22 in C- or N-terminus abolished or diminished bird-to-bird transmission, respectively $[14,90]$. In the last case, the MDV genome copy number in feathers was reduced compared to the wild type [14].

To date, no cellular component has been found to be associated with the higher viral replication in feather follicles and specifically to its ability to produce a large quantity of infectious viral particles. The development of new molecular models of keratinocytes permissive to MDV infection in our laboratory may help solve this problem [91].

\section{Excretion of vaccinating strains and pathogenic strains of MDV}

The three currently available vaccines (HVT, GaHV-3 SB1, and GaHV-2 CV1988/Rispens) induce a nonsterilizing immune response which protects against tumor development. The Rispens strain is to date the best available vaccine against the most virulent strains of MDV. Because MDV is strictly associated with infected cells in culture, GaHV-2 vaccines are constituted of infected cells frozen in liquid nitrogen, a unique formulation for an antiviral vaccine. In poultry houses, vaccines are administered to 1-day-old chicks manually or in the embryo in ovo, 23 days before hatching using an automated injection system. All vaccinating strains replicate in feather follicles and their DNA is detectable in feather tips by qPCR $[59,64]$. The kinetics of detection of the genome of these strains is similar to that of pathogenic strains. For instance, the genome of the Rispens strains is detectable 4 to 7 days post-vaccination in the feather tips by qPCR $[64,92]$, and the number of genome copies increases to reach 100-fold that measured in other tissues [64]. The number of copies of the Rispens genome at 21 days post-vaccination is highly variable between birds [93]. Whether quantitation of the genome of vaccinating strains in feathers by qPCR allows to evaluate the level of protection of the flock in poultry farms remains to be determined $[93,94]$.

It is well established that vaccination does not block the infection of feather follicles by pathogenic strains and viral production, during experimental infection or in 
poultry farms $[57,62,95]$. In the past several years, qPCR methods were developed to discriminate between vaccinating strains and virulent strains. In particular, point mutation in the pp38 gene allowed to distinguish the attenuated Rispens strain from most pathogenic strains in the field [95]. The impact of vaccinating viruses on the replication of pathogenic viruses and vice versa is starting to be elucidated. Several studies have shown an increase in viral load for the HVT genome in feather after MDV infection, suggesting that infection by a virulent virus could increase the replication of the vaccinating virus $[62,96]$. This has not been observed with the Rispens homologous vaccinating strain [92]. The accumulation of the pathogenic strain RB-1B in feathers is reduced by approximately 10 times after vaccination with the Rispens strain, but its kinetics is not shorter (within the 21 days of the study) [92]. Nair hypothesized that vaccination allows pathogenic MDV strains to unobtrusively spread in poultry houses and could contribute to the evolution of viruses towards more virulent genotypes [17].

\section{Immune response in the skin of MDV-infected chickens}

Studies of the host immune response in feathers after infection with a highly virulent virus (like RB-1B) or by a vaccinating virus (like Rispens or HVT) show an increase in the expression of pro-inflammatory cytokine genes, particularly gamma-interferon, as well as an infiltration of CD4+ with or without CD8+ T lymphocytes $[97,98]$. The above mentioned results suggest that the immune response in feather follicles is relatively ineffective at blocking MDV replication in that tissue and at preventing its excretion in the environment. The cellular and molecular mechanisms that help protect against MDV replication and its excretion from the skin, are currently poorly characterized. Greater knowledge of these mechanisms would substantially help reduce the spreading of pathogenic strains in poultry houses.

\section{Conclusions}

In the past several years, the interactions between MDV and the skin have seen a renewed interest. Many studies have helped show that pathogenic viruses are excreted from feather follicles at high levels in the environment despite vaccination. The development of new techniques to measure the viral load from feather tips and dust has been essential to obtain these data. Blocking the excretion of pathogenic MDV is considered to date as a major goal to stop and prevent the evolution of MDV towards more pathogenic genotypes. Fundamentally however, many questions remain unanswered, particularly the molecular mechanisms and cellular components involved in the atypical morphogenesis of MDV in the epithelium of feather follicles leading to high production of infectious virions and environmental contamination.

\section{Abbreviations}

CEF, chicken embryonic fibroblasts; EGFP, Enhanced Green Fluorescent Protein; GaHV-3, Gallid herpesvirus 3; HHV-1, Human herpesvirus 1; HVT, Turkey herpesvirus (MeHV, Meleagrid herpesvirus); MD, Marek's disease; MDV, Marek's disease virus (GaHV-2, Gallid herpesvirus 2); mRFP, monomeric Red Fluorescent Protein; pi, post-infection; PRV, Pseudorabies virus (Suid herpesvirus 1); qPCR, quantitative PCR; TEM, transmission electron microscopy.

\section{Lexicon}

Barbs: Thick appendages located on both sides of the beak.

Bursa of Fabricius: Primary lymphoid organ specific of birds in which B lymphocytes are generated and selected. B lymphocytes exit from the bursa only at hatching. This organ, which is located on the dorsal side of the cloaca, regresses after 12 weeks of age and completely disappears.

Feather follicle: Region of the skin where a feather is formed and anchored (one follicle harbors one feather). The follicle ensures the renewal of the feather after a physiological or accidental loss.

Apteric skin: Area of the skin devoid of appendages (feathers, scales, etc.).

\section{Competing interests}

The authors declare that they have no competing interests.

\section{Authors' contributions}

$M C$ wrote the part related to chicken skin and feather follicles, prepared the figures and table. CD wrote the parts related to Marek's disease virus. Both authors read and approved the manuscript.

\section{Acknowledgements}

We are grateful to T. Larcher and the INRA APEX core facility for histology (UMR 703, Oniris, Nantes, France) for providing the HES pictures of healthy chicken skin J-F. Vautherot for providing the picture of the MDV infected feather follicle, D. Dhouailly and P. Djian for providing the anti-keratin 14 and involucrin antibodies. We also thank $L$. Fragnet-Trapp for her comments on the manuscript and $F$. Paillard for editing the manuscript. M. Couteaudier was financially supported by a graduate grant of Region Centre. Our research on chicken skin models for MDV replication is supported by the French National Research Agency (ANR) in the framework of an ERA-NET EMIDA program, called MADISPREAD.

Received: 11 December 2013 Accepted: 10 March 2014 Published: 3 April 2014

\section{References}

1. Morrow C, Fehler F: Marek's disease: a worldwide problem. In Marek's disease: an evolving problem. Edited by Davison F, Nair V. London: Elsevier Academic Press; 2004:49-61.

2. Churchill AE, Biggs PM: Agent of Marek's disease in tissue culture. Nature 1967, 215:528-530.

3. Nazerian K, Solomon JJ, Witter RL, Burmester BR: Studies on the etiology of Marek's disease. II. Finding of a herpesvirus in cell culture. Proc Soc Exp Biol Med 1968, 127:177-182.

4. Tulman ER, Afonso CL, Lu Z, Zsak L, Rock DL, Kutish GF: The genome of a very virulent Marek's disease virus. J Virol 2000, 74:7980-7988.

5. Churchill AE, Payne LN, Chubb RC: Immunization against Marek's disease using a live attenuated virus. Nature 1969, 221:744-747. 
6. Witter RL, Nazerian K, Purchase HG, Burgoyne GH: Isolation from turkeys of a cell-associated herpesvirus antigenically related to Marek's disease virus. Am J Vet Res 1970, 31:525-538.

7. Okazaki W, Purchase HG, Burmester BR: Protection against Marek's disease by vaccination with a herpesvirus of turkeys. Avian Dis 1970, 14:413-429.

8. Schat KA, Calnek BW: Characterization of an apparently nononcogenic Marek's disease virus. J Natl Cancer Inst 1978, 60:1075-1082.

9. Rispens BH, van Vloten H, Mastenbroek N, Maas HJ, Schat KA: Control of Marek's disease in the Netherlands. I. Isolation of an avirulent Marek's disease virus (strain CVI 988) and its use in laboratory vaccination trials. Avian Dis 1972, 16:108-125.

10. Calnek BW: Marek's disease-a model for herpesvirus oncology. Crit Rev Microbiol 1986, 12:293-320.

11. Calnek BW: Pathogenesis of Marek's disease virus infection. Curr Top Microbiol Immunol 2001, 255:25-55.

12. Baaten BJ, Staines KA, Smith LP, Skinner H, Davison TF, Butter C: Early replication in pulmonary $B$ cells after infection with Marek's disease herpesvirus by the respiratory route. Viral Immunol 2009, 22:431-444

13. Mwangi WN, Smith LP, Baigent SJ, Beal RK, Nair V, Smith AL: Clonal structure of rapid-onset MDV-driven CD4+ lymphomas and responding CD8+ T cells. PLoS Pathog 2011, 7:e1001337.

14. Rémy S, Blondeau C, Le Vern Y, Lemesle M, Vautherot J-F, Denesvre C: Fluorescent tagging of VP22 in N-terminus reveals that VP22 favors Marek's disease virus virulence in chickens and allows morphogenesis study in MD tumor cells. Vet Res 2013, 44:125.

15. St Hill CA, Silva RF, Sharma JM: Detection and localization of avian alphaherpesviruses in embryonic tissues following in ovo exposure. Virus Res 2004, 100:243-248.

16. Gimeno IM: Future strategies for controlling Marek's disease. In Marek's disease: an evolving problem. Edited by Davison F, Nair V. London: Elsevier Academic Press; 2004:186-199.

17. Nair V: Evolution of Marek's disease - a paradigm for incessant race between the pathogen and the host. Vet J 2005, 170:175-183.

18. Davison F, Nair V: Marek's disease: An evolving problem. London: Elsevier Academic Press; 2004.

19. Osterrieder N, Kamil JP, Schumacher D, Tischer BK, Trapp S: Marek's disease virus: from miasma to model. Nat Rev Microbiol 2006, 4:283-294.

20. Schat KA, Nair V: Marek's Disease. In Disease of Poultry. Edited by Saif YM. Blackwell Publishing Ltd: Ames; 2008:452-514.

21. Lucas AM, Stettenheim PR: Avian Anatomy Integument. Agriculture Handbook 1972, 362:346-629.

22. Spearman RIC, Hardy JA: Integument, Volume 3. London: Academic Press; 1985.

23. Vanhoutteghem A, Djian P: Basonuclin 2: an extremely conserved homolog of the zinc finger protein basonuclin. Proc Natl Acad Sci U S A 2004, 101:3468-3473.

24. Vanhoutteghem A, Londero T, Djian P, Ghinea N: Serial cultivation of chicken keratinocytes, a composite cell type that accumulates lipids and synthesizes a novel beta-keratin. Differentiation 2004, 72:123-137.

25. Candi E, Schmidt R, Melino G: The cornified envelope: a model of cell death in the skin. Nat Rev Mol Cell Biol 2005, 6:328-340.

26. Ng CS, Wu P, Foley J, Foley A, McDonald ML, Juan WT, Huang CJ, Lai YT, Lo WS, Chen CF, Leal SM, Zhang H, Widelitz RB, Patel PI, Li WH, Chuong CM: The chicken frizzle feather is due to an alpha-keratin (KRT75) mutation that causes a defective rachis. PLoS Genet 2012, 8:e1002748.

27. Vanhoutteghem A, Djian P, Green H: Ancient origin of the gene encoding involucrin, a precursor of the cross-linked envelope of epidermis and related epithelia. Proc Natl Acad Sci U S A 2008, 105:15481-15486.

28. Perez Torres A, Millan Aldaco DA: la antigens are expressed on ATPase-positive dendritic cells in chicken epidermis. J Anat 1994, 184:591-596.

29. Igyarto BZ, Lacko E, Olah I, Magyar A: Characterization of chicken epidermal dendritic cells. Immunology 2006, 119:278-288.

30. Ortolani-Machado C, De Freitas P, Borges ME, Faraco C: Special features of dermal melanocytes in white silky chicken embryos. Anat Rec (Hoboken) 2008, 291:55-64

31. Presland RB, Gregg K, Molloy PL, Morris CP, Crocker LA, Rogers GE: Avian keratin genes. I. A molecular analysis of the structure and expression of a group of feather keratin genes. J Mol Biol 1989, 209:549-559.

32. Yu M, Yue Z, Wu P, Wu DY, Mayer JA, Medina M, Widelitz RB, Jiang TX, Chuong CM: The developmental biology of feather follicles. Int J Dev Biol 2004, 48:181-191.
33. Yue Z, Jiang TX, Widelitz RB, Chuong CM: Mapping stem cell activities in the feather follicle. Nature 2005, 438:1026-1029.

34. Lin CM, Jiang TX, Widelitz RB, Chuong CM: Molecular signaling in feather morphogenesis. Curr Opin Cell Biol 2006, 18:730-741.

35. Lin SJ, Foley J, Jiang TX, Yeh CY, Wu P, Foley A, Yen CM, Huang YC, Cheng HC, Chen CF, Reeder B, Jee SH, Widelitz RB, Chuong CM: Topology of feather melanocyte progenitor niche allows complex pigment patterns to emerge. Science 2013, 340:1442-1445.

36. Sevoian M, Chamberlain DM, Larose RN: Avian lymphomatosis. V. Air-borne transmission. Avian Dis 1963, 7:102-105.

37. Biggs PM, Payne LN: Studies on Marek's disease. 1. Experimental transmission. J Natl Cancer Inst 1967, 39:267-280.

38. Calnek BW, Hitchner SB: Localization of viral antigen in chickens infected with Marek's disease herpesvirus. J Natl Cancer Inst 1969, 43:935-949.

39. Beasley JN, Patterson LT, McWade DH: Transmission of Marek's disease by poultry house dust and chicken dander. Am J Vet Res 1970, 31:339-344.

40. Jurajda V, Klimes B: Presence and survival of Marek's disease agent in dust. Avian Dis 1970, 14:188-190.

41. Calnek BW, Adldinger HK, Kahn DE: Feather follicle epithelium: a source of enveloped and infectious cell-free herpesvirus from Marek's disease. Avian Dis 1970, 14:219-233.

42. Nazerian K, Witter RL: Cell-free transmission and in vivo replication of Marek's disease virus. J Virol 1970, 5:388-397.

43. Carrozza JH, Fredrickson TN, Prince RP, Liginbuhl RE: Role of desquamated epithelial cells in transmission of Marek's disease. Avian Dis 1973, 17:767-781.

44. Witter RL, Burgoyne GH, Burmester BR: Survival of Marek's disease agent in litter and droppings. Avian Dis 1968, 12:522-530.

45. Purchase HG: Virus-specific immunofluorescent and precipitin antigens and cell-free virus in the tissues of birds infected with Marek's disease. Cancer Res 1898-1908, 1970:30

46. Davidson I, Maray T, Malkinson M, Becker Y: Detection of Marek's disease virus antigens and DNA in feathers from infected chickens. J Virol Methods 1986, 13:231-244.

47. Rong-Fu W, Beasley JN, Cao WW, Slavik MF, Johnson MG: Development of PCR method specific for Marek's disease virus. Mol Cell Probes 1993, 7:127-131.

48. Davidson I, Borenshtain R: The feather tips of commercial chickens are a favorable source of DNA for the amplification of Marek's disease virus and avian leukosis virus, subgroup J. Avian Pathol 2002, 31:237-240.

49. Baigent SJ, Petherbridge LJ, Howes K, Smith LP, Currie RJ, Nair VK: Absolute quantitation of Marek's disease virus genome copy number in chicken feather and lymphocyte samples using real-time PCR. J Virol Methods 2005, 123:53-64.

50. Abdul-Careem MF, Hunter BD, Nagy E, Read LR, Sanei B, Spencer JL, Sharif S: Development of a real-time PCR assay using SYBR Green chemistry for monitoring Marek's disease virus genome load in feather tips. J Virol Methods 2006, 133:34-40

51. Islam A, Cheetham BF, Mahony TJ, Young PL, Walkden-Brown SW: Absolute quantitation of Marek's disease virus and Herpesvirus of turkeys in chicken lymphocyte, feather tip and dust samples using real-time PCR. J Virol Methods 2006, 132:127-134.

52. Renz KG, Islam A, Cheetham BF, Walkden-Brown SW: Absolute quantification using real-time polymerase chain reaction of Marek's disease virus serotype 2 in field dust samples, feather tips and spleens. J Virol Methods 2006, 135:186-191.

53. Davidson I, Borenshtain R: Novel applications of feather tip extracts from MDV-infected chickens; diagnosis of commercial broilers, whole genome separation by PFGE and synchronic mucosal infection. FEMS Immunol Med Microbiol 2003, 38:199-203.

54. Holland MS, Mackenzie CD, Bull RW, Silva RF: Latent turkey herpesvirus infection in lymphoid, nervous, and feather tissues of chickens. Avian Dis 1998, 42:292-299

55. Wozniakowski G, Samorek-Salamonowicz E, Kozdrun W: Rapid detection of Marek's disease virus in feather follicles by loop-mediated amplification. Avian Dis 2011, 55:462-467.

56. Dunn JR, Silva RF, Lee LF, Witter RL: Competition between two virulent Marek's disease virus strains in vivo. Avian Pathol 2012, 41:267-275.

57. Baigent SJ, Kgosana L, Gamawa A, Smith LP, Read AF, Nair V: Relationship between levels of very virulent MDV in Poultry dust and in feather tips from vaccinated chickens. Avian Dis 2013, 57:440-447.

58. Walkden-Brown S, Islam A, Groves P, Rubite A, Sharpe SM, Burgess S: Development, application, and results of routine monitoring of Marek's 
disease virus in broiler house dust using real-time quantitative PCR Avian Dis 2013, 57:544-554.

59. Cortes AL, Montiel ER, Lemiere S, Gimeno IM: Comparison of blood and feather pulp samples for the diagnosis of Marek's disease and for monitoring Marek's disease vaccination by real time-PCR. Avian Dis 2011 55:302-310.

60. Malkinson M, Davidson I, Strenger C, Weisman Y, Maray T, Levy H, Becker Y: Kinetics of the appearance of Marek's disease virus DNA and antigens in the feathers of chickens. Avian Pathol 1989, 18:735-744.

61. Niikura M, Witter RL, Jang HK, Ono M, Mikami T, Silva RF: MDV glycoprotein $\mathrm{D}$ is expressed in the feather follicle epithelium of infected chickens. Acta Virol 1999, 43:159-163.

62. Islam A, Walkden-Brown SW: Quantitative profiling of the shedding rate of the three Marek's disease virus (MDV) serotypes reveals that challenge with virulent MDV markedly increases shedding of vaccinal viruses. J Gen Virol 2007, 88:2121-2128.

63. Jarosinski KW: Marek's disease virus late protein expression in feather follicle epithelial cells as early as 8 days postinfection. Avian Dis 2012, 56:725-731.

64. Baigent SJ, Smith LP, Currie RJ, Nair VK: Replication kinetics of Marek's disease vaccine virus in feathers and lymphoid tissues using PCR and virus isolation. J Gen Virol 2005, 86:2989-2998.

65. Jarosinski KW: Dual infection and superinfection inhibition of epithelia skin cells by two alphaherpesviruses co-occur in the natural host. PLoS One 2012, 7:e37428.

66. Cho BR, Kenzy SG: Virologic and serologic studies of zoo birds for Marek's disease virus infection. Infect Immun 1975, 11:809-814.

67. Lin JA, Kitagawa H, Ono M, Iwanaga R, Kodama H, Mikami T: Isolation of serotype 2 Marek's disease virus from birds belonging to genus Gallus in Japan. Avian Dis 1990, 34:336-344.

68. Bacon LD, Hunt HD, Cheng HH: Genetic resistance to Marek's disease. Curr Top Microbiol Immunol 2001, 255:121-141.

69. Smith J, Sadeyen JR, Paton IR, Hocking PM, Salmon N, Fife M, Nair V, Burt DW, Kaiser P: Systems analysis of immune responses in Marek's disease virus-infected chickens identifies a gene involved in susceptibility and highlights a possible novel pathogenicity mechanism. J Virol 2011, 85:11146-11158.

70. Heidari M, Fitzgerald SD, Zhang HM, Silva RF, Lee LF, Dunn JR: Marek's disease virus-induced skin leukosis in scaleless chickens: tumor development in the absence of feather follicles. Avian Dis 2007, 51:713-718.

71. Wick G, Andersson L, Hala K, Gershwin ME, Selmi C, Erf GF, Lamont SJ, Sgonc R: Avian models with spontaneous autoimmune diseases. Adv Immunol 2006, 92:71-117.

72. Erf GF, Bersi TK, Wang X, Sreekumar GP, Smyth JR Jr: Herpesvirus connection in the expression of autoimmune vitiligo in Smyth line chickens. Pigment Cell Res 2001, 14:40-46.

73. Helmboldt CF, Wills FK, Frazier MN: Field observations of the pathology of skin leukosis in Gallus gallus. Avian Dis 1963, 7:402-411.

74. Sharma JM, Davis WC, Kenzy SG: Etiologic relationship of skin tumors (skin leukosis) of chickens to Marek's disease. J Natl Cancer Inst 1970, 44:901-911.

75. Lapen RF, Piper RC, Kenzy SG: Cutaneous changes associated with Marek's disease of chickens. J Natl Cancer Inst 1970, 45:941-950.

76. Mohanty GC, Sharma RN, Gopalkrishna S, Pradhan HK, Rajya BS: Lesions of Marek's disease in some modified cutaneous appendages of chicken Poultry Sci 1976, 55:40-44.

77. Pass DA: The pathology of the avian integument: a review. Avian Pathol 1989, 18:1-72

78. Granzow H, Klupp BG, Fuchs W, Veits J, Osterrieder N, Mettenleiter TC: Egress of alphaherpesviruses: comparative ultrastructural study. J Virol 2001, 75:3675-3684.

79. Stackpole CW: Herpes-type virus of the frog renal adenocarcinoma. I. Virus development in tumor transplants maintained at low temperature. $J$ Virol 1969, 4:75-93.

80. Granzow H, Weiland F, Jons A, Klupp BG, Karger A, Mettenleiter TC: Ultrastructural analysis of the replication cycle of pseudorabies virus in cell culture: a reassessment. J Virol 2072-2082, 1997:71.

81. Enquist LW, Husak PJ, Banfield BW, Smith GA: Infection and spread of alphaherpesviruses in the nervous system. Adv Virus Res 1998, 51:237-347.
82. Skepper JN, Whiteley A, Browne H, Minson A: Herpes simplex virus nucleocapsids mature to progeny virions by an envelopment -> deenvelopment $->$ reenvelopment pathway. J Virol 2001, 75:5697-5702.

83. Mettenleiter TC, Klupp BG, Granzow H: Herpesvirus assembly: an update. Virus Res 2009, 143:222-234.

84. Denesvre C, Blondeau C, Lemesle M, Le Vern Y, Vautherot D, Roingeard P, Vautherot JF: Morphogenesis of a highly replicative EGFPVP22 recombinant Marek's disease virus (MDV) in cell culture. J Virol 2007, 81:12348-12359.

85. Denesvre C: Marek's diseases virus morphogenesis. Avian Dis 2013, 57:340-350

86. Calnek BW, Ubertini T, Adldinger HK: Viral antigen, virus particles, and infectivity of tissues from chickens with Marek's disease. J Nat/ Cancer Inst 1970, 45:341-351.

87. Johnson EA, Burke CN, Fredrickson TN, DiCapua RA: Morphogenesis of marek's disease virus in feather follicle epithelium. J Natl Cancer Inst 1975, 55:89-99.

88. Ono M, Jang HK, Maeda K, Kawaguchi Y, Tohya Y, Niikura M, Mikami T: Detection of Marek's disease virus serotype 1 (MDV1) glycoprotein D in MDV1-infected chick embryo fibroblasts. J Vet Med Sci 1996, 58:777-780.

89. Anderson AS, Parcells MS, Morgan RW: The glycoprotein D (US6) homolog is not essential for oncogenicity or horizontal transmission of Marek's disease virus. J Virol 1998, 72:2548-2553.

90. Jarosinski KW, Arndt S, Kaufer BB, Osterrieder N: Fluorescently tagged pUL47 of Marek's disease virus reveals differential tissue expression of the tegument protein in vivo. J Virol 2011, 86:2428-2436.

91. Couteaudier M, Courvoisier-Guyader K, Pain B, Denesvre C, Vautherot J-F: Susceptibility of chicken embryonic stem cell-derived keratinocytes to Marek's disease virus infection. In World Veterinary Poultry Aassociation Congress. Nantes; 2013. 19-23 August 2013.

92. Haq K, Fear $T$, Ibraheem A, Abdul-Careem MF, Sharif S: Influence of vaccination with CVI988/Rispens on load and replication of a very virulent Marek's disease virus strain in feathers of chickens. Avian Pathol 2012, 41:69-75.

93. Baigent SJ, Smith LP, Nair VK, Currie RJ: Vaccinal control of Marek's disease: current challenges, and future strategies to maximize protection. Vet Immunol Immunopathol 2006, 112:78-86.

94. Baigent SJ, Smith LP, Currie RJ, Nair VK: Correlation of Marek's disease herpesvirus vaccine virus genome load in feather tips with protection, using an experimental challenge model. Avian Pathol 2007, 36:467-474.

95. Baigent SJ, Le Galludec H, Nair V: Real-time PCR for differential quantification of CVI988 vaccine virus and virulent strains of Marek's disease virus. In World Veterinary Poultry Aassociation Congress: 2013. Nantes; 2013. 19-23 august 2013.

96. Levy H, Maray T, Davidson I, Malkinson M, Becker Y: Replication of Marek's disease virus in chicken feather tips containing vaccinal turkey herpesvirus DNA. Avian Pathol 1991, 20:35-44

97. Abdul-Careem MF, Hunter BD, Sarson AJ, Parvizi P, Haghighi HR, Read L, Heidari M, Sharif S: Host responses are induced in feathers of chickens infected with Marek's disease virus. Virology 2008, 370:323-332.

98. Abdul-Careem MF, Hunter DB, Shanmuganathan S, Haghighi HR, Read L, Heidari M, Sharif S: Cellular and cytokine responses in feathers of chickens vaccinated against Marek's disease. Vet Immunol Immunopathol 2008, 126:362-366

doi:10.1186/1297-9716-45-36

Cite this article as: Couteaudier and Denesvre: Marek's disease virus and skin interactions. Veterinary Research 2014 45:36 